\title{
Identification of the Neural Pathway for Reinforcement of Feeding when Aplysia Learn that Food Is Inedible
}

\author{
Miriam Schwarz and Abraham J. Susswein \\ Department of Life Sciences, Bar-llan University, Ramat-Gan 52 100, Israel
}

Bilateral sectioning of the esophageal nerves that innervate the gut of Aplysia was found to have profound effect on response decrement to inedible food: Time to criterion for cessation of feeding was elevated, no memory of the decrement was present $\mathbf{2 4} \mathbf{~ h r}$ after training, and motor patterning during training was altered. The parametric features of response decrement to sustained lip stimulation were examined to determine their resemblance to parameters of response decrement to inedible food after esophageal nerve sectioning. Parameters of response decrement were similar, indicating that after esophageal nerve sectioning response decrement is likely to be the result of sustained lip stimulation. Bilateral nerve sectioning had no effect on decrement due to sustained lip stimulation. Unilateral lesions and lesions of either of the two major divisions of the esophageal nerves had no effect on learning that food was inedible. The data indicate that bilateral nerve sectioning eliminates all stimuli causing negative reinforcment of feeding due to failure to consume food. Based on the data in this and the previous paper, a model is presented suggesting sites of action and mechanisms for learning that foods are edible or inedible in Aplysia.

An important problem in neuroscience is determining the relationship between mechanisms underlying different forms of plasticity affecting the same efferent pathway. The present paper examines the relationship between two types of plasticity causing inhibition of feeding in Aplysia: decrement due to learning that a food is inedible and decrement caused by sustained stimulation of the lips with food (presumably due to sensory adaptation or habituation).

In the preceding paper (Susswein et al., 1986), data were presented indicating that the reinforcing consequences of feeding behavior affect subsequent responsiveness to food. Successful consumption of food acts as a positive reinforcer of feeding, while failed attempts to consume food act as negative reinforcers. Potentially, any of a number of stimuli could signal Aplysia as to whether they have succeeded in consuming food. These stimuli could be carried into the CNS via afferents traveling in a number of peripheral nerves. In a preliminary report (Schwarz and Susswein, 1984), we presented data suggesting that the esophageal nerves innervating the gut carry afferents that inform the CNS about whether food has been consumed; these afferents are necessary for reinforcement of feeding. When gut inputs that reinforce feeding are not activated, decreased feeding occurs because of other processes. The present paper examines this hypothesis in greater detail. The parametric features of inhibi-

\footnotetext{
Received Apr. 1, 1985; revised July 2, 1985; accepted July 3, 1985.

We would like to thank Irving Kupfermann and Jeffrey Camhi for comments on an earlier version of the manuscript. This work was supported in part by Israel Institute for Psychobiology, Charles E. Smith Family Foundation Grant 7/84.

Correspondence should be addressed to Dr. A. Susswein at the above address.

Copyright (c) 1986 Society for Neuroscience $0270-6474 / 86 / 051528-09 \$ 02.00 / 0$
}

tion of feeding were determined in animals in which the esophageal nerves were cut to determine whether such treatment specifically eliminates the inhibition of feeding that depends on negative reinforcement, while leaving unaffected processes that do not depend on reinforcement, such as feeding inhibition caused by sustained lip stimulation. Three such parameters were examined: (1) the time to criterion to cease responding to food; (2) the persistence of this response decrement; and (3) the pattern of the response decrement.

The data presented below indicate that inhibition of feeding due to sustained lip stimulation is unaffected by denervation of the gut, while inhibition due to learning that food is inedible is severely affected. After denervation of the gut, all behavioral changes during training can be attributed to feeding inhibition arising from sustained lip stimulation. Data are also presented indicating that both major branches of the esophageal nerves bilaterally carry inputs that can produce reinforcement of feeding.

\section{Materials and Methods}

Procedures and sites for obtaining, storing, and training Aplysia have been described in the previous paper (Susswein et al., 1986). Experiments were performed at the same time as those reported in the previous paper but on different animals.

\section{Sustained lip stimulation}

In experiments in which the effects of sustained lip stimulation were examined, netted Ulva was touched to the lips, producing a bite. Food was withdrawn at the response and, consequently, did not enter the buccal cavity and elicit swallowing. This procedure was continued until animals stopped responding to food. The criterion for cessation of responses was the same as that in experiments on learned changes in feeding behavior (Susswein et al., 1986)-one response in a $3 \mathrm{~min}$ period.

\section{Surgical procedures}

Surgical techniques were similar to those of Kupfermann (1974b). Aplysia were anesthetized by injecting isotonic $\mathrm{MgCl}_{2}$ (25-35\% of body weight) into the hemocoel. Animals were then pinned through the tail and tentacles ventral side up to the waxed bottom of a dissecting pan that was set at an angle, with the head upward. A cut just below the rostral edge of the foot exposed the buccal ganglia. In sham-operated animals, the esophageal nerves were exposed and the ganglion manipulated. After manipulation or sectioning of the appropriate nerves, the body wall was closed with 6-0 surgical silk thread (Teva Pharmaceuticals, Israel). All behavioral procedures were performed 1 week after surgery. After the behavioral procedure, animals were dissected, and the stumps of the cut nerves were identified to confirm the surgical procedures.

\section{Anatomy of the esophageal nerves}

The anatomy of the esophageal nerves was investigated in Aplysia cal ifornica (Pacific Biomarine, Venice, CA) by staining with methylene blue intravitam according to the method of Pantin (1946). This solution was perfused through the circulatory system of Aplysia by simultaneously cannulating the anterior aorta and the gastrointestinal artery, 


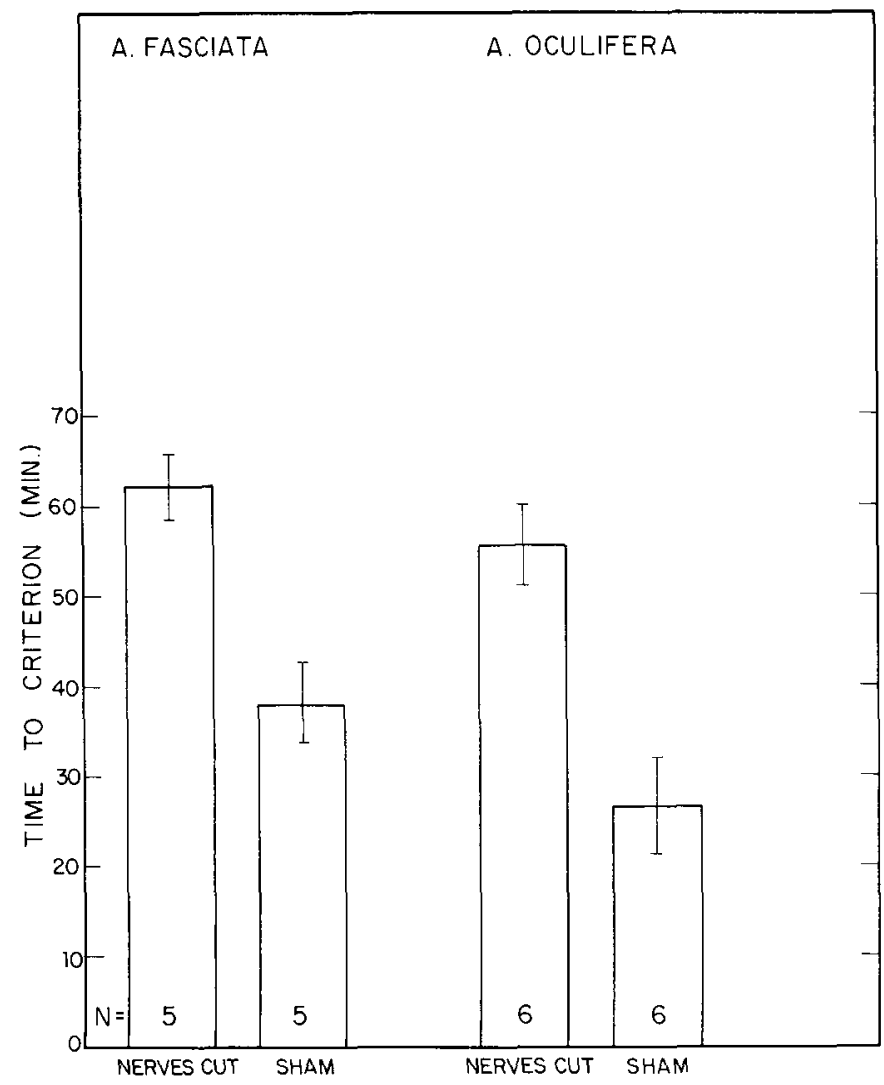

Figure 1. Time to criterion of cessation of response to netted Ulva that was permitted to enter the mouth and elicit failed swallows in $A$. fasciata (left) and A. oculifera (right). Data are for both animals in which the esophageal nerves were bilaterally cut, and for sham-operated controls. SE bars are shown.

both of which send branches to the gut. In unstained material, the esophageal nerves in $A$. fasciata and A. oculifer $a$ were found to be similar in all respects to those of $A$. californica.

\section{Results}

\section{Effects of nerve section on learning that food is inedible}

To determine whether bilateral sectioning of the esophageal nerves affects learning that a food is inedible, the esophageal nerves of $A$. fasciata and oculifera were bilaterally cut. A week after surgery, these animals were fed inedible netted $U l v a$, allowing the food to enter the mouth and elicit failed attempts to swallow the food. The time to cessation of responsiveness to food was determined. Animals were run in a blind procedure along with sham-operated controls.

\section{Time to criterion}

Figure 1 shows the time to cessation of feeding on inedible netted Ulva. Time to criterion was over twice as long as in shamoperated animals in both species of Aplysia (for $A$. oculifera: $p<0.001, t=4.15, d f=10$; for A. fasciata: $p<0.01, t=4.04$, $d f=8$; two-tailed $t$ test). Time to criterion was similar to that when the response decrement was due to sustained lip stimulation (see below, Fig. 6). The data indicate that in esophageal nerve-sectioned animals time to criterion is more easily explained as resulting from processes that terminate feeding after sustained lip stimulation than from the pairing of feeding with negative reinforcement.

\section{Memory of training}

To test the effects of bilateral nerve sectioning on memory, six A. fasciata were trained on inedible netted Ulva for 2 consec-

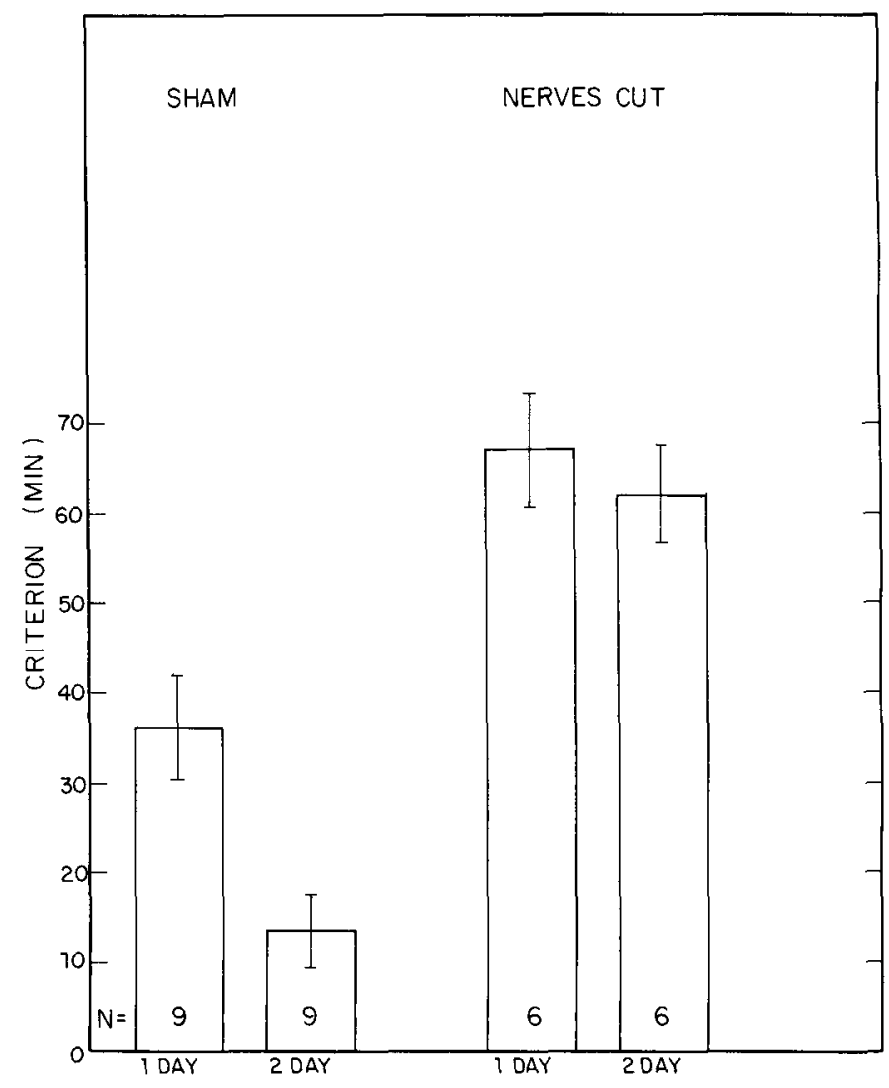

Figure 2. Time to criterion of cessation of response to food on 2 consecutive days in animals trained on netted Ulva that was allowed to become stuck in the buccal cavity and elicit failed swallows. Data are for both animals in which the esophageal nerves were bilaterally cut (right) and sham-operated controls (left). Number of animals in each group $(N)$ and SE bars are shown.

utive days a week after the esophageal nerves were cut; nine sham-operated controls were run along with these animals in a blind procedure. Figure 2 shows that retraining denervated animals $24 \mathrm{hr}$ after the initial training does not produce savings in time to criterion $(0.5<p<0.9, t=0.64, d f=5$; paired $t$ test). In both the initial and second training sessions, time to criterion was comparable to that observed during sustained stimulation of the lips, when food does not enter the buccal cavity. By contrast, retraining sham-operated animals produced clear savings in time to stop responding $(p<0.01, t=5.0, d f=$ 8 ), similar to that previously reported in intact animals (Susswein et al., 1986).

\section{Pattern of response decrement}

Figure $3 A$ illustrates the pattern of responses observed during training with inedible netted Ulva in $A$. fasciata in which the esophageal nerves were bilaterally sectioned. Comparable data for $A$. oculifera have been presented previously (Schwarz and Susswein, 1984). The data indicate that feeding responses leading to entry of food and subsequent swallowing occur throughout most of the training session. Figure $3 B$ shows the pattern of responses in sham-operated controls. Similar to the pattern observed in intact animals (Susswein et al., 1986), feeding responses become ineffective as training progresses; when food does enter the buccal cavity, it remains there for a shorter time.

To quantify these effects, the time to criterion was divided into 10 cqual time periods, and for cach animal the percentage of effective feeding responses was calculated for each period throughout training sessions. In animals whose nerves were cut, there was no tendency for progressive increase in responses that fail to lead to food entry (Fig. 4). Rate of successful responses 
A

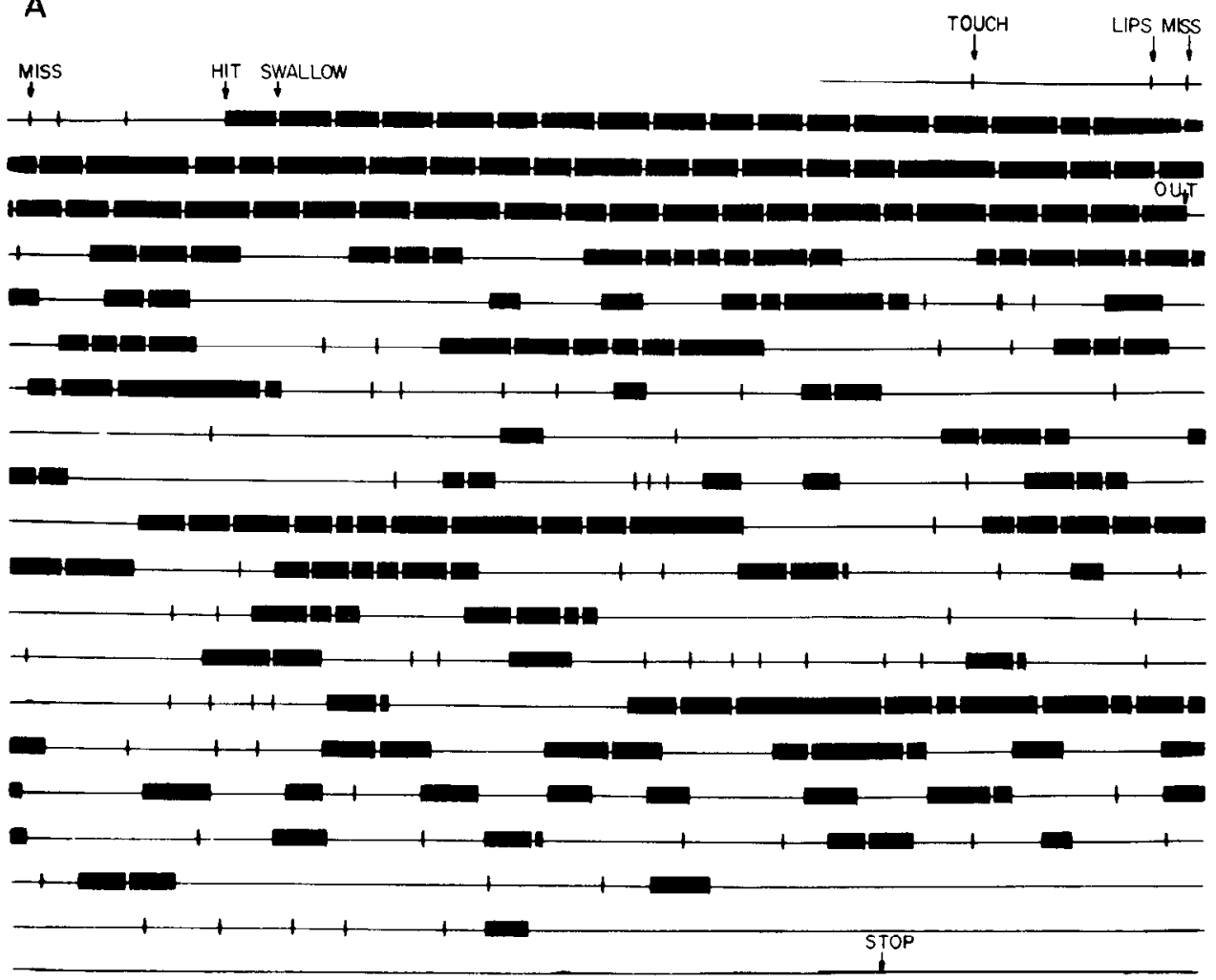

Figure 3. A, Continuous record from a pen writer showing response pattern during training in $A$. fasciata in which the esophageal nerves were bilaterally cut. Symbols used to mark each type of event are indicated in the first two lines of each record [these are identical to those used in the preceding paper (Susswein et al., 1986)]. $B$, Response pattern during training in a sham-operated $A$. fasciata.

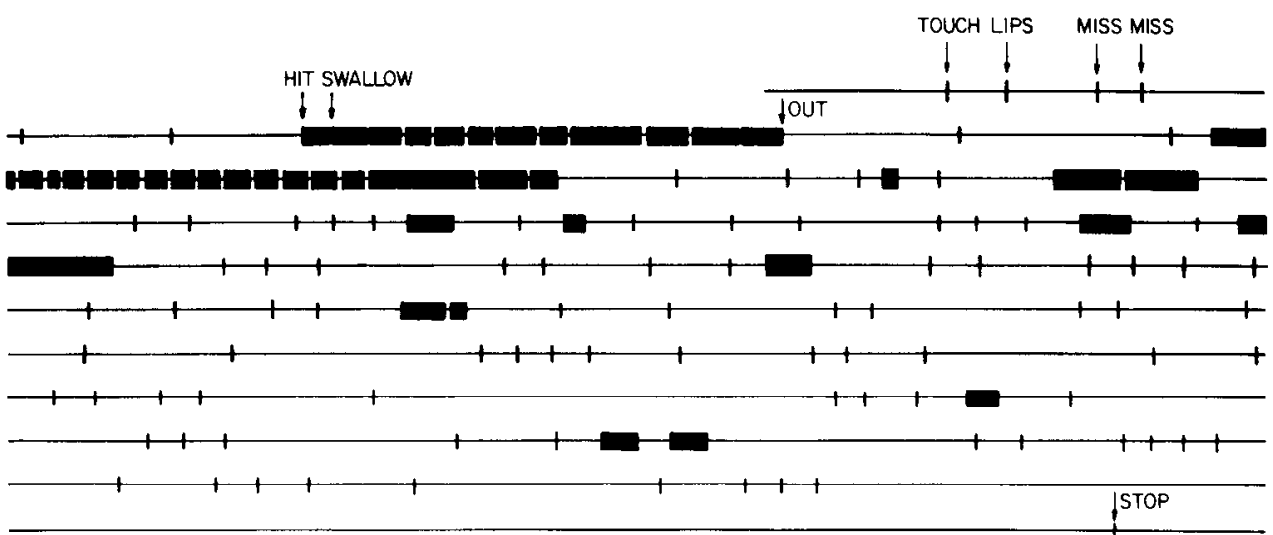

was not significantly affected by the training procedure (for $A$. oculifera: $0.25<p<0.50, H^{\prime}=9.03, d f=9$; for $A$. fasciata: $0.1<p<0.25, H^{\prime}=13.7, d f=9$; Kruskal-Wallis ranked "oneway analysis of variance"). By contrast, in sham-operated controls, the pattern of the response decrement was similar to that previously observed in nonoperated animals (Susswein et al., 1986). Similar to previous results in intact animals, a significant decrease was observed in the percentage of effective feeding responses that occurred during training (for $A$. oculifera: $p<$ $0.025, H^{\prime}=21.0, d f=9$; for A. fasciata: $p<0.05, H^{\prime}=17.9$, $d f=9$; Kruskal-Wallis ranked one-way analysis of variance).

The time food remained in the buccal cavity was also measured. The effects of training on this parameter are particularly evident toward the end of a training session (Susswein et al., 1986). Figure 5 shows the percentage of time that food remained in the buccal cavity during the second half of the training session in animals with bilaterally cut esophageal nerves and in shamoperated controls. This value was higher in denervated animals $(p<0.001, t=5.63, d f=10$ for A. oculifera; $p<0.05, t=$ 2.23, $d f=17$ for $A$. fasciata; two-tailed $t$ test).

\section{Parameters of sustained lip stimulation}

The data presented above suggest that stimuli informing $A p l y s i a$ about whether food has been successfully consumed reach the CNS via the esophageal nerves, and that bilateral section of these nerves abolishes the ability to learn that food is inedible. If this hypothesis is correct, the question arises as to why animals nonetheless stop responding to inedible food after the esophageal nerves are severed. The most likely explanation is that this cessation of feeding is due to sensory adaptation or habituation or to other processes initiated by extended stimulation of the lips. To determine whether sustained lip stimulation accounts 


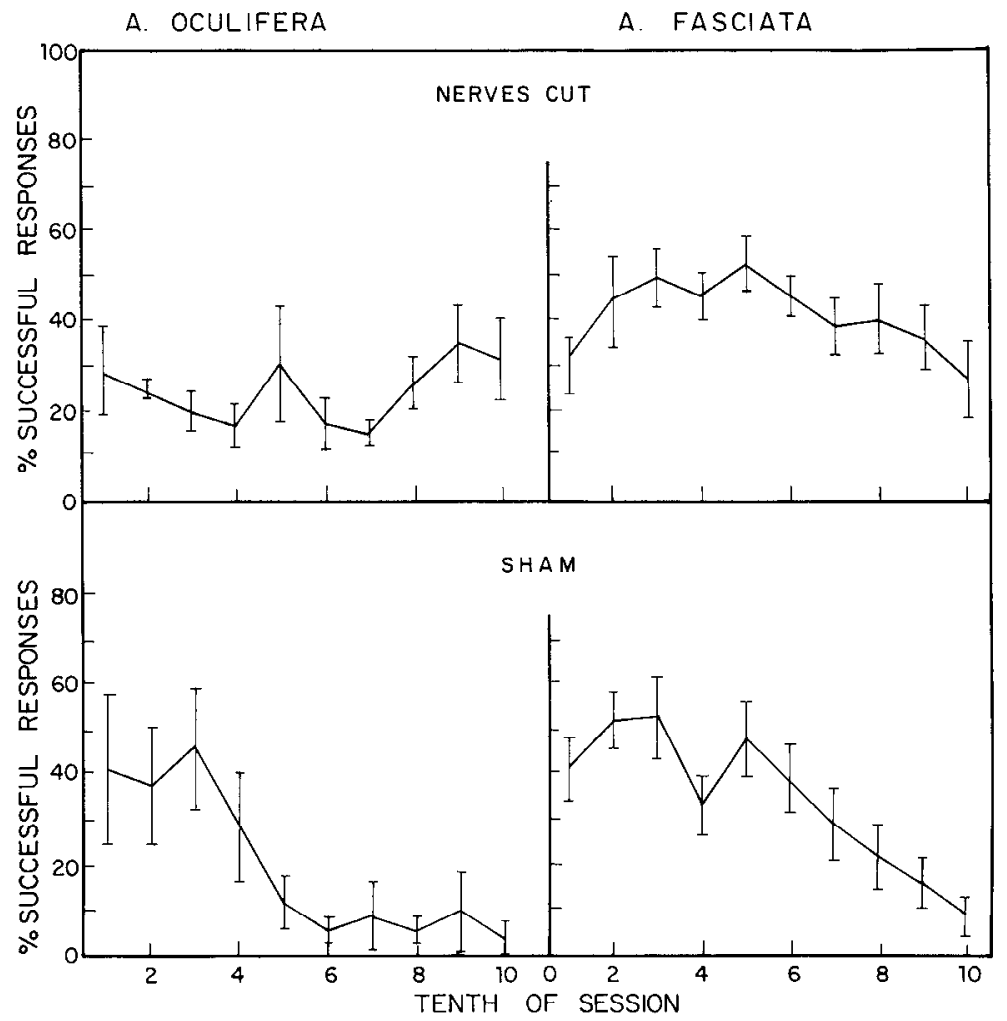

Figure 4. Percentage of effective feeding responses in each of 10 segments of the training sessions in $A$. fasciata and $A$. oculifera with bilaterally cut esophageal nerves (top) and in sham-operated controls (bottom). SE bars are shown.

for the cessation of feeding after the esophageal nerves have been sectioned, we examined a number of feeding parameters that are affected in intact animals whose lips are stimulated for extended periods of time. We examined whether parameters of the decrement were similar to those of the response decrement to inedible food observed after the esophageal nerves were sectioned.

In these experiments, food stimulated the lips but was withdrawn when the animal responsed, preventing food entry into the buccal cavity. Other than briefly withdrawing the food at the response, the lips were tonically stimulated continuously, and Aplysia attempted to bite, until they eventually stopped responding.

\section{Time to criterion and memory}

Figure 6 shows the time to criterion to stop responding to netted Ulva in a group of five $A$. fasciata whose lips were stimulated in two training sessions $24 \mathrm{hr}$ apart. No decrease in time to criterion occurred during the second session $(p>0.4, t=0.82$; paired $t$ test): Time to criterion on both days was similar to that observed when esophageal-sectioned animals were trained on inedible food (see Figs. 1 and 2).

\section{Pattern of response decrement}

Figure 7 shows a pen recording of a session in which a single A. fasciata was stimulated with netted $U l v a$; food was withdrawn when the animal responsed, restricting the stimulus to the lips. Unlike the response pattern during training on inedible food (Susswein et al., 1986), in which clear behavioral changes were observed well before cessation of feeding, the feeding response to food stimuli restricted to the lips was relatively unchanged until close to cessation of responsiveness. To quantify the effects of sustained lip stimulation, the time until criterion for cessation of feeding in the first session was divided into 10 equal intervals. For each animal, we calculated the percentage of the total number of responses that occurred during each interval. No significant difference was found in the percentage of responses that occurred in each interval $(p>0.25, F(1.066,9)$, $d f=50)$.

\section{Effects of nerve sectioning on sustained lip stimulation}

These data are consistent with the hypothesis that the decline in responsiveness after sectioning of the esophageal nerves is caused by the same processes that led to response decrement with sustained lip stimulation, since time to criterion and pattern were similar under both conditions. If this hypothesis is correct, one would expect that bilateral esophageal nerve sectioning would not affect the decrement due to sustained lip stimulation. The data presented in this section support this hypothesis.

The esophageal nerves of six $A$. fasciata were bilaterally cut. A week after surgery these animals were stimulated with netted Ulva on 2 consecutive days; the food was withdrawn when the animals responded, preventing food entry into the buccal cavity. On both days, the procedure was continued until animals stopped responding to food (criterion was one response in a $3 \mathrm{~min}$ period). Animals were run in a blind procedure along with five sham-operated controls.

\section{Time to criterion and memory}

Figure 8 shows the time to criterion of response decrement on the first and second days in these animals. No significant difference was found between the four groups $(F=0.14, d f=3,18$; one-way analysis of variance). Time to criterion in all cases was similar to that observed in intact $A$. fasciata undergoing the same procedure (Fig. 6). These data indicate that time to criterion and memory are not affected by sectioning of the esophageal nerves when decrement is the result of sustained lip stimulation.

\section{Pattern of response decrement}

To examine whether the response rate pattern is affected by esophageal nerve sectioning, the time to criterion on the first training day was divided into 10 equal periods and the per- 


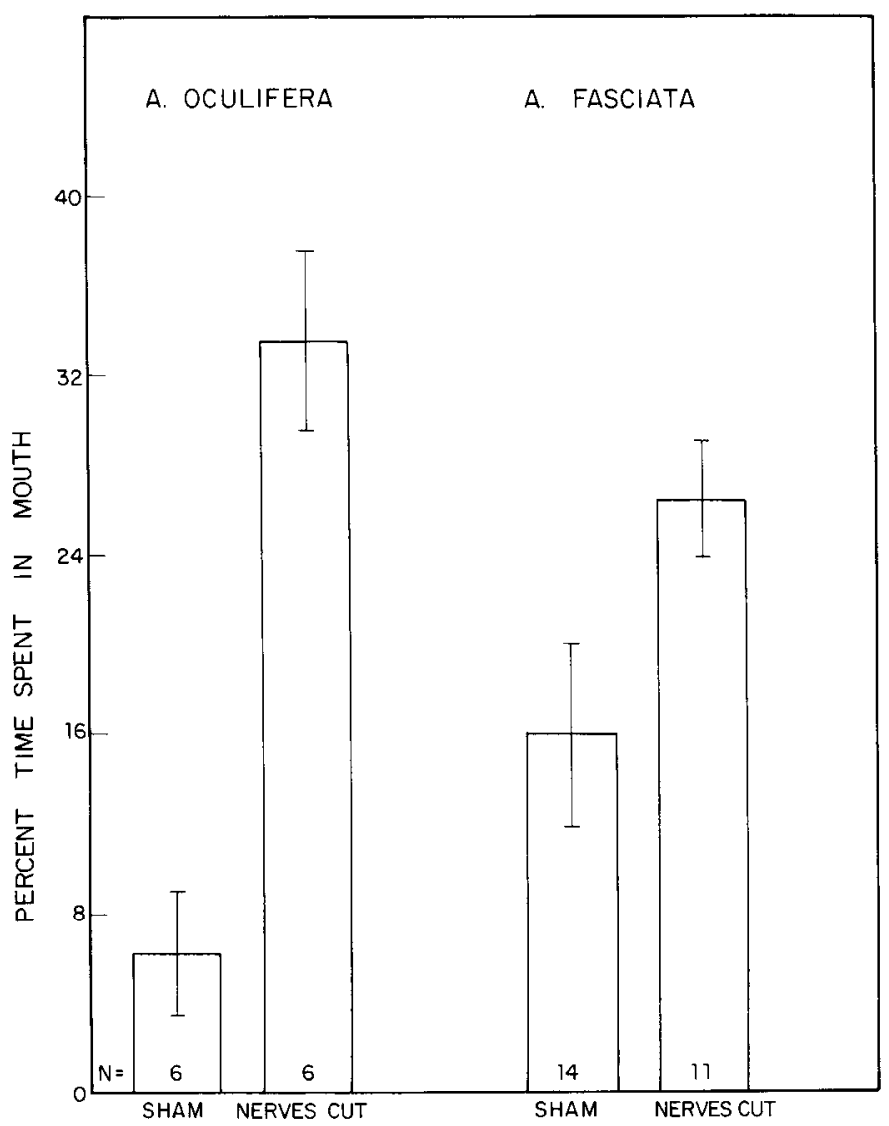

Figure 5. Percentage of time food remained in the buccal cavity during the second half of the training session in both $A$. oculifera (left) and $A$. fasciata (right) with bilaterally cut esophageal nerves, and in shamoperated controls. Number of animals in each group $(N)$ and SE bars are shown.

centage of feeding responses occuring in each was measured for all nerve-sectioned and sham-operated animals. Figure 9 shows the feeding response rates during the sessions in which the animals were exposed to food that did not enter the buccal cavity. Two-way analysis of variance shows that there was no significant difference in response rate during sustained lip stimulation between sham-operated and nerve-sectioned animals; as in unoperated animals (Schwarz et al., 1986), feeding response rate was unchanged until the criterion for cessation of response was reached $(F=1.37, d f=9,90$ for variability between tenths to criterion; $F=0.02, d f=1,90$ for variability betwecn nervesectioned and control animals; two-way analysis of variance). These data indicate that the response pattern is unchanged by cutting the esophageal nerves.

\section{Anatomy of the esophageal nerves and effects of partial nerve section}

The esophageal nerves carry information to and from the gut and the CNS, specifically the buccal ganglia. As an initial step in exploring the nature of the information carried by the nerves that affect learning, the anatomy of the nerves was investigated. Subsequently, specific branches of the nerve were sectioned to determine the inputs needed for learning that food is inedible.

\section{Anatomy of the esophageal nerve}

The anatomy of the anterior portion of the esophageal nerve is illustrated in Figure 10. The nerve bifurcates very soon after it leaves the buccal ganglion. One branch, the posterior division (MacFarland, 1909), can be traced down the length of the crop (the anterior portion of the gut) and into the anterior gizzard.

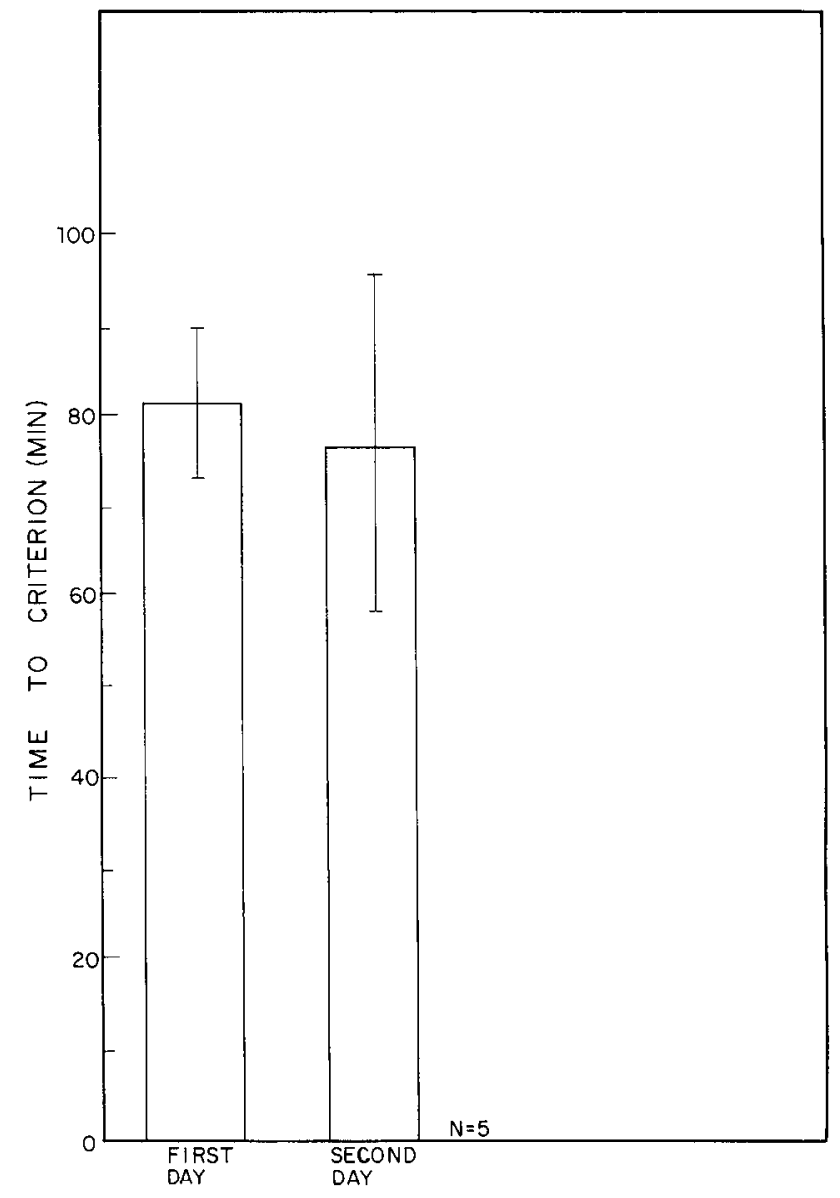

Figure 6. Time to criterion for cessation of feeding on 2 consecutive days in $A$. fasciata stimulated with netted Ulva that was withdrawn when animal responded. Time to criterion on Days 1 and 2 were not significantly different. Number of animals run $(N)$ and SE bars are shown.

The nerve periodically sends off small branches that anastomose and form a complex nerve net surrounding the crop. Peripheral cells, which appear to be neurons, are frequently found at branch points. Some of the more anterior branches of the posterior division turn anteriorly and travel toward the buccal mass. The other major branch of the esophageal nerve, the anterior division (MacFarland, 1909), branches off at a sharp angle from the posterior division and runs laterally. Branches of the anterior division were obscrved running to the salivary gland and buccal mass, and down the crop. In addition, connections between the anterior division and buccal nerve one (Gardner, 1977) were occasionally observed. Peripheral cells were also frequently found on branch points of this nerve. Some peripheral cells were consistently found at the same location. Two particularly large cells were observed on a branch of the anterior division that runs to the salivary gland.

\section{Partial nerve section}

Experiments were performed to determine whether information necessary for learning that food is inedible is carried exclusively by either the right or left esophageal nerve, or by its anterior or posterior divisions.

Anterior versus posterior division lesions. To determine whether effects of lesions are due to separation from the CNS of either the anterior or posterior divisions of the esophageal nerves alone, the anterior division was bilaterally cut in six $A$. fasciata and the posterior division in seven. One week after surgery, animals were trained with inedible netted Ulva in a blind procedure with 


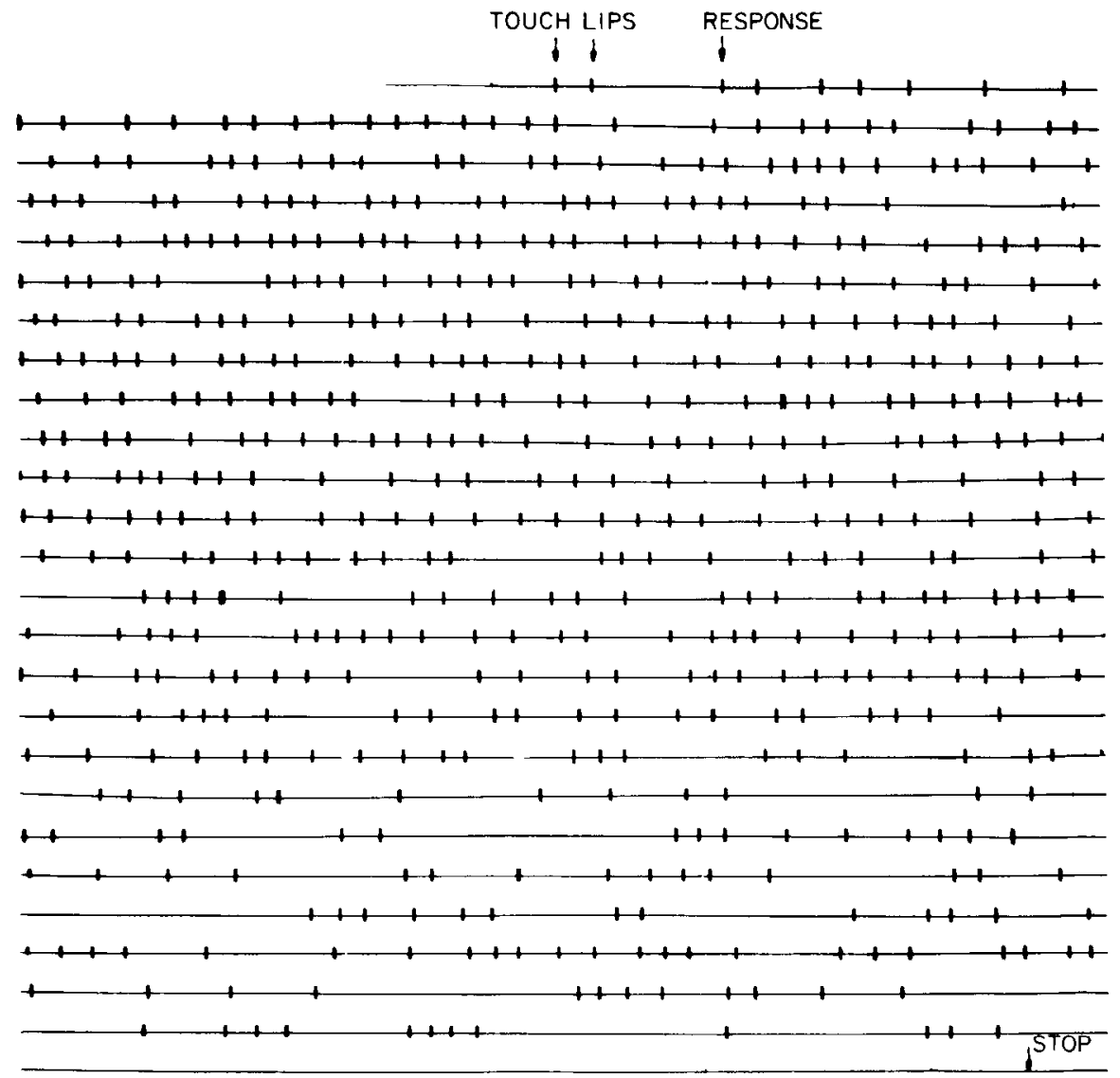

Figure 7. Continuous record from a pen recorder showing response rate in a single $\boldsymbol{A}$. fasciata to lip stimulation with netted Ulva that was withdrawn at the response to prevent food entering the buccal cavity. Each mark represents a feeding response. sham-operated animals run as controls. Figure 11 shows that time to criterion was not significantly increased by either procedure $(p>0.25, F=1.16, d f=4,22$; one-way analysis of variance between all treatments shown in Fig. 11). These data indicate that both major divisions of the esophageal nerves carry information that is sufficient to produce reinforcement.

Unilateral lesions. In four $A$. fasciata, the right esophageal nerve was unilaterally sectioned, and in five, the left nerve was lesioned. One week later, animals were trained with inedible netted $U l v a$, and time to criterion was measured. Sham-operated animals were run along with experimentals in a blind procedure. Figure 11 shows that time to criterion in animals with unilaterally sectioned esophageal nerve was not significantly different from that of sham-operated controls $(p>0.25, F(1.16), d f=4$ and 24; one-way analysis of variance). Although the effect was not significant, sectioning of the left nerve appeared to decrease time to criterion, rather than increase it. The reason for this is not known, but it could reflect the fact that sectioning cuts off a source of tonic facilitation of feeding in the gut. Previous data (Susswcin ct al., 1984) have shown that gut inputs facilitate feeding.

\section{Discussion}

The esophageal nerves carry information to and from the gut and the CNS, specifically the buccal ganglia. The data presented above indicate that some information carried by this nerve is essential in signaling the reinforcing consequences of feeding. The decreased responsiveness to inedible food that occurs after these nerves are cut can be entirely accounted for by the decrement due to sustained lip stimulation, which is itself unaffected by sectioning the esophageal nerves. Both major branches of the bilateral esophageal nerves apparently carry inputs for reinforcement.

The esophageal nerve is a compound nerve subserving many functions, both sensory and motor. The nature of the information for reinforcement could be related to any of the tasks performed by afferents or efferents in the nerve.

\section{Sensory effects of the esophageal nerve}

Filling the crop with food or non-nutritive bulk produces stimulus-graded satiation as a result of passive stretching of the gut (Susswein and Kupfermann, 1975a, b; Susswein et al., 1976). Bilaterally sectioning the esophageal nerves abolishes satiation (B. Kuslansky, K. R. Weiss and I. Kupfermann, personal communication). Successful eating of small quantities of food produces excitation of feeding, as measured by an increased duration of food arousal, probably caused by activation of gut chemoreceptors (Susswein et al., 1984). Gut afferents also modulatc fecding in other gastropods. Satiation has been demonstrated in Pleurobranchaea (Davis et al., 1977), Limax (Reingold and Gelperin, 1980), Ariolimax (Senseman, 1978), and Navanax (Susswein and Bennett, 1979). Facilitation of feeding by gut inputs has been observed in Philine, where esophageal proprioceptors excite elements responsible for gencrating the feeding pattern (Dorsett and Sigger, 1981; Sigger and Dorsett, 1981). In Pleurobranchaea, stimulation of the stomatogastric nerve innervating the gut drives patterned motor output resembling that occurring during ingestion (Croll and Davis, 1982) and egestion of food (Croll and Davis, 1982; McClellan, 1982). In Navanax, entry of food into the esophagus causes animals to maintain suction on the prey (Susswein and Bennett, 1979).

\section{Motor effects of the esophageal nerve}

In Aplysia, bilateral sectioning of the esophageal nerves causes a relaxation of the esophageal sphincter, allowing reflux of food from the crop back into the buccal cavity (Susswein, 1975). Esophageal efferents also produce peristaltic and mixing movements (I. Kupfermann and K. R. Weiss, personal communi- 


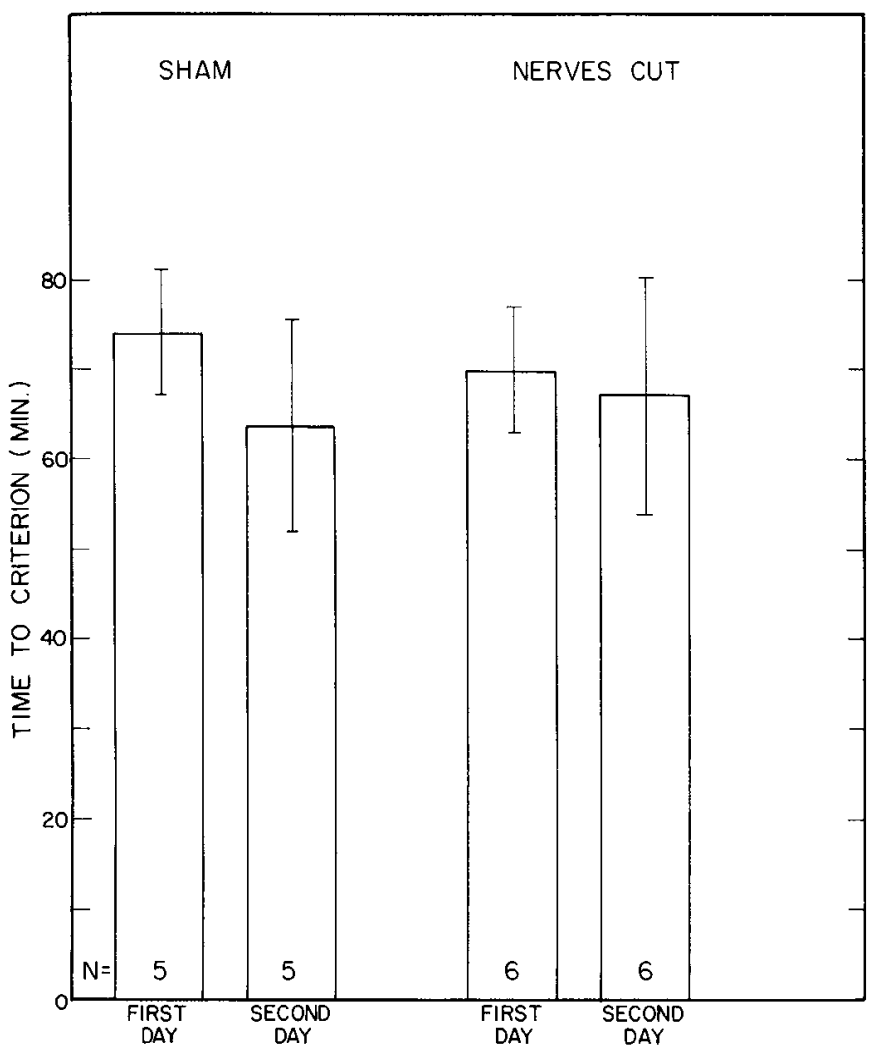

Figure 8. Time to criterion on cessation of response to food on 2 consecutive days when netted Ulva was touched to the external lips and withdrawn when the animal responsed. Cessation was likely to be due to adaptation or habituation. Data arc for animals in which the csophageal nerves were bilaterally cut (right) and for sham-operated controls (left). Number of animals in each group $(N)$ and SE bars are shown.

cation). The nerve also contains large quantities of the peptide $\mathrm{SCPb}$, which modulates the buccal musculature (Lloyd et al., 1984). In other gastropods, peripheral cells similar to those in the esophageal nerve of Aplysia innervate the salivary gland (Barber, 1983; Gorman and Mirolli, 1969).

The data presented above, along with that in the previous paper (Susswein et al., 1986), can be explained by the model presented in Figure 12. The model is an attempt to explain how learning that food is inedible may be related to other phenomena that result in inhibition of feeding, such as sustained lip stimulation, and how learning that food is edible is related to learning that it is inedible.

Afferents that sense food stimuli are presented as exciting pattern generators for various movements. The afferents (Foods $A$ and $B$ ) are at least one synapse into the CNS, since both mechanical and chemical stimuli determine their specificity. Two pattern generators organize feeding movements: They are labeled as producing effective and ineffective responses, since the nature of the movements they produce has not been conclusively determined. Effective feeding responses are likely to be bites (Kupfermann, 1974a), but the possibility exists that some effective responses represent movements that have not yet been characterized. Some ineffective movements are undoubtedly rejection responses that actively push food away from the mouth (Kupfermann, 1974a); often the push is felt (Susswein et al., 1986). However, many responses are ineffective for other reasons. Some ineffective responses may be swallows, which are effective in pushing food from the buccal cavity into the gut, but are ineffective in leading to food entry into the buccal cavity. This hypothesis is consistent with the observation that swallow rate increases when animals learn that food is inedible (Susswein

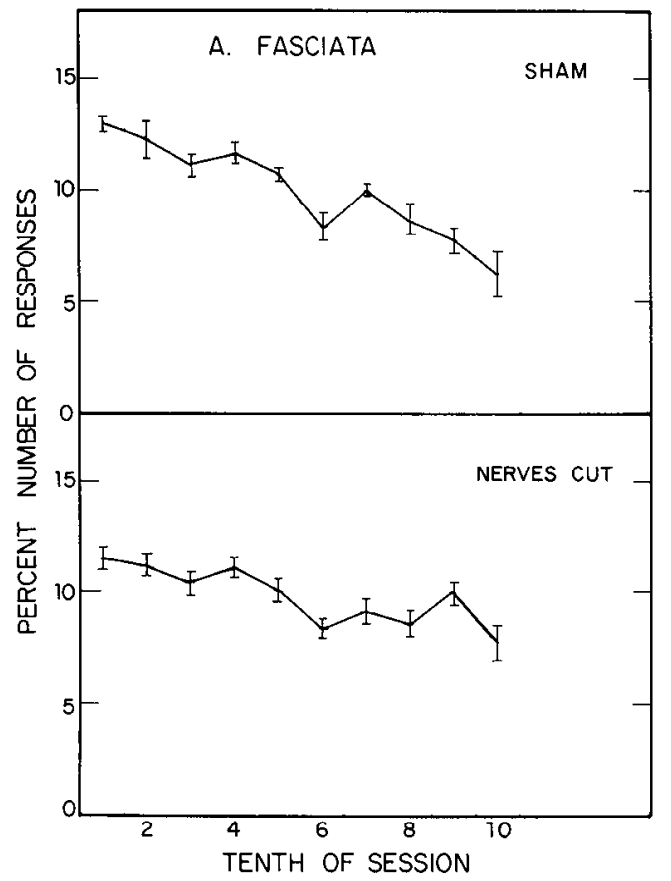

Figure 9. Normalized response rate in A. fasciata to food stimuli that were withdrawn when the animal responsed. For each animal, the total number of feeding responses was counted, and the total time to criterion was measured. Time to criterion was divided into 10 equal time periods, and the percentage of the total number of feeding responses occurring in each was calculated. Means for the whole population were then determined. Data are for animals in which the esophageal nerves were bilaterally cut (bottom) and for sham-operated controls (top). SE bars are shown.

et al., 1986). Pattern generators for effective and ineffective responses are presented as being mutually inhibitory. Motoneurons driven by pattern generators are in part common, in part unique. The likelihood that a pattern generator will be active is increased by excitatory lip inputs. Initially effective responses predominate, since input is stronger, or excitability is higher.

In addition to exciting pattern generators for feeding movements, lip afferents also excite an arousal system for feeding and other behaviors (Weiss et al., 1981), as well as pattern generators for various head and foot movements (Kupfermann, 1974a). The output of the arousal system can be monitored by recording from the metacerebral cell (MCC) (Kupfermann and Weiss, 1982), which directly facilitates motoneurons and muscles (Weiss

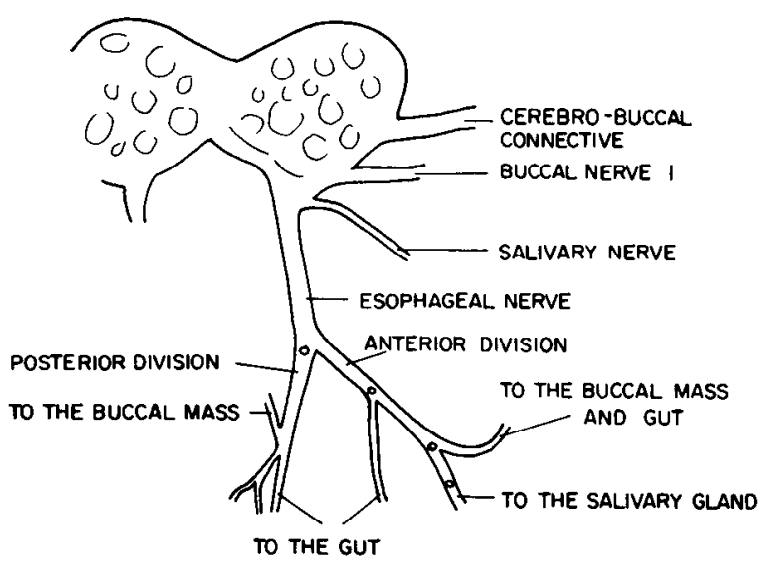

Figure 10. Drawing of the anterior portion of the esophageal nerve. The anterior and posterior divisions of the nerve are shown. Also shown are the positions of some peripheral cells, which were repeatedly found. 


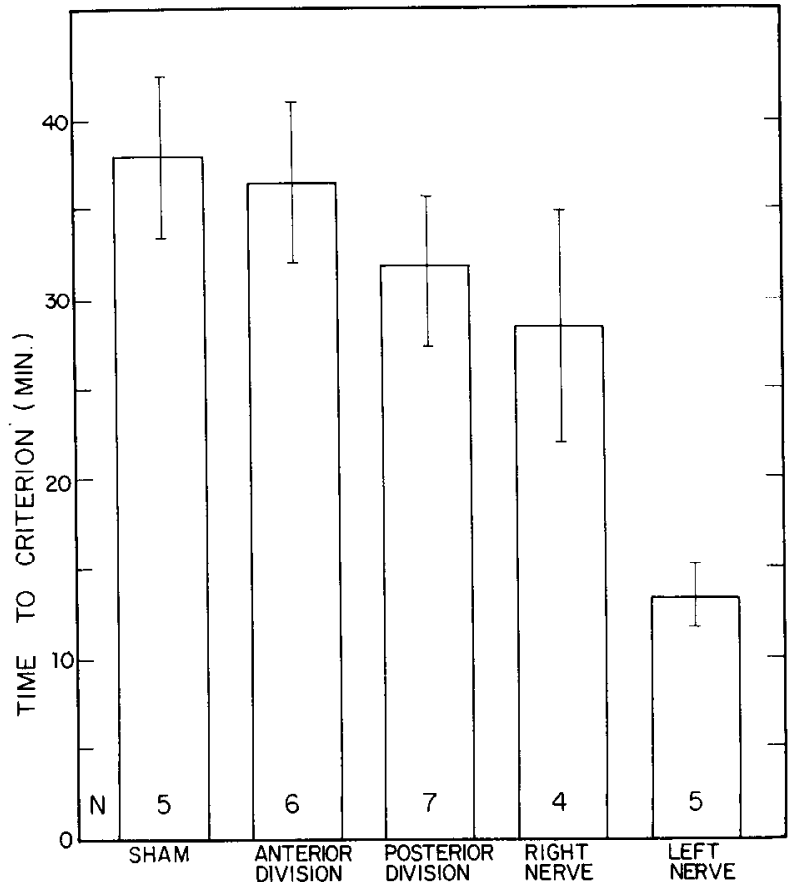

Figure 11. Time to criterion of cessation of response in $A$. fasciata trained on netted Ulva that elicited failed swallowing. Data are shown from animals in which only the anterior or posterior division of the esophageal nerves was bilaterally cut, or in which the entire right or left esophageal nerve was unilaterally cut. Data are also shown for shamoperated controls. Number of animals in each group $(N)$ and SE bars are shown. et al., 1978); the arousal system also affects other behaviors (Weiss et al., 1981) by means that are, at present, unknown.

The model postulates that successful food consumption facilitates afferents onto the pattern generator for effective responses, and failed attempts to consume food facilitate afferents onto the pattern generator for ineffective responses. Training an animal that a food is edible or inedible differentially regulates the output of a sensory channel to a particular feeding pattern generator, but does not affect outputs of a sensory channel to other pattern generators or to the arousal system. This aspect of the model explains changes in motor patterning that occur when Aplysia learn that foods are edible or inedible, and also explains why animals remain aroused after learning that food is inedible (Susswein et al., 1986). If facilitation of neither pattern generator occurs, either because the facilitatory inputs are removed by sectioning the esophageal nerves or because food does not enter the buccal cavity, sensory adaptation, habituation, or other processes initiated by sustained lip stimulation result in decreased responsiveness. Inhibition due to sustained lip stimulation produces a decrease in outputs to all pattern generators and to the arousal system. This aspect of the model leads one to expect that inhibition of feeding with sustained lip input should produce motor effects differing from those of inhibition due to learning, should be stimulus-specific, and should produce a decrease in the arousal level. All these expectations have been verified (Figs. 3, 7; also M. Schwarz, S. Markovich, and A. J. Susswein, unpublished observations). Data presented elsewhere also indicate that satiation directly inhibits feeding motor systems (M. Schwarz, S. Markovich, and A. J. Susswein, unpublished observations), this is also shown in Figure 12.

The most parsimonious explanation for specificity to pairing is that simultaneous activation of an input pathway and a fa-

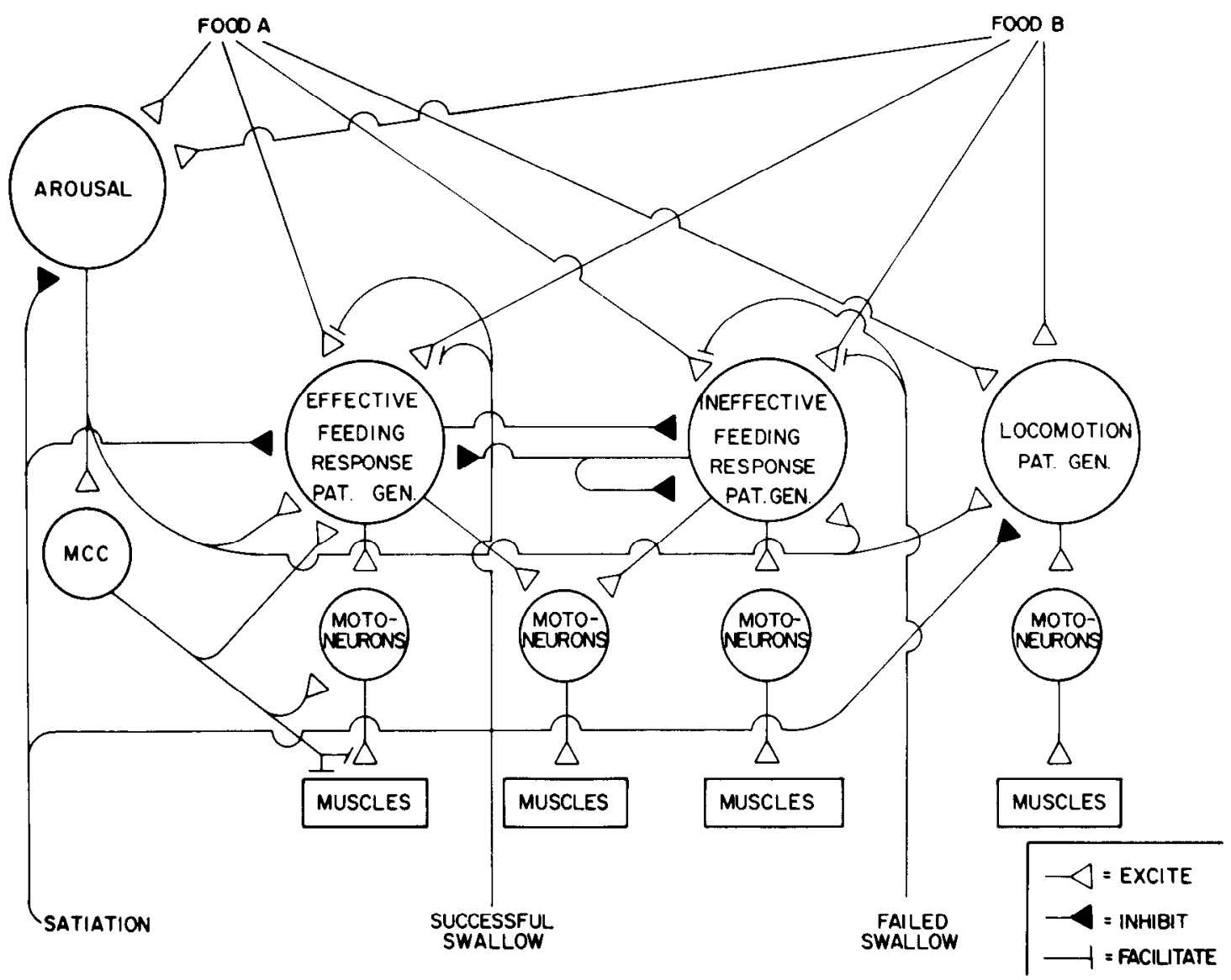

Figure 12. Model summarizing the results of the data presented above. Sites and mechanisms that may account for the data are suggested. See text for complete explanation. 
cilitatory pathway produces more effective facilitation than does nonsimultaneous activation. Cellular and molecular mechanisms for pairing-specific facilitation may be similar to those that occur in pairing-specific facilitation of gill and tail withdrawal (Carew et al., 1983; Hawkins et al., 1983; Kandel and Schwartz, 1982; Walters and Byrne, 1983). Nonpaired activation of the facilitatory pathway will produce arousal-like effects that are likely to be much smaller than those due to pairing. Arousal of feeding after successful food consumption has been demonstrated (Susswein et al., 1984).

After successful feeding, behavior is terminated by satiation or by inhibition resulting from sustained lip stimulation. Time to criterion and pattern in Aplysia fed edible netted foods (Susswein et al., 1986) are consistent with the hypothesis that feeding is terminated by sustained lip stimulation. Behavior is terminated after unsuccessful feeding because ineffective responses are self-limiting, and at some point such movements cease. I. Kupfermann (personal communication) has obtained evidence that rejection of nonfood objects placed in the buccal cavity is a self-terminating process.

The model suggests that differential regulation of different branches of a sensory channel may underlie the choice between different (or even opposite) motor tasks at different times. Clark and Kandel (1984) have recently demonstrated differential facilitation of different branches of a sensory cell in the gill and siphon withdrawal system of Aplysia.

The model can account for some features of instrumental learning in higher animals by postulating that pattern-generating elements for various movements receive multimodal inputs, and that reinforcement changes the likelihood that a specific input will firc a pattern generator. Previous studies have indicated that sensory inputs initiate multiple, often opposite processes (Groves and Thompson, 1970; Hurvich and Jameson, 1957; Solomon and Corbit, 1974). Expression of a process at a particular time is a consequence of the modulation of behavior by experiential or motivational variables (Groves and Thompson, 1970; Solomon and Corbit, 1974). Research on mammals has also indicated that aversive stimuli, such as failed swallowing, produce inhibition indirectly by initiating competing behaviors (Bolles, 1967; Crawford and Masterson, 1982; Masterson and Crawford, 1982).

The proposed model makes a number of explicit, testable predictions about neural circuits and mechanisms that produce learning and other forms of modulation of feeding in Aplysia. These predictions can be directly verified in future cellular studies.

\section{References}

Barber, A. (1983) Nervous control of salivary secretion in the carnivorous mollusc Philine aperta. J. Exp. Biol. 107: 331-348.

Bolles, R. C. (1967) Theory of Motivation, Harper \& Row, New York.

Carew, T. J., R. D. Hawkins, and E. R. Kandel (1983) Differential classical conditioning of a defensive withdrawal reflex in $A$. californica. Science 219: 397-400.

Clark, G. A., and E. R. Kandel (1984) Branch-specific heterosynaptic facilitation in Aplysia siphon sensory cells. Proc. Natl. Acad. Sci. USA 81: 2577-2581

Crawford, M., and F. A. Masterson (1982) Species-specific defence reactions and avoidance learning. Pavlovian I. Biol. Sci. 17: 157180.

Croll, R. P., and W. J. Davis (1982) Motor program switching in Pleurobranchaea: Ingestion and egestion in the reduced preparation. J. Comp. Physiol. 147: 143-154.

Davis, W. J., G. J. Mpitsos, M. Pinneo, and J. Ram (1977) Modification of the behavioral hierarchy in Pleurobranchaea. I. Satiation and feeding motivation. J. Comp. Physiol. 117: 99-125.

Dorsett, D. A., and J. N. Sigger (1981) Sensory fields and properties of the oesophageal proprioceptors in the mollusc Philine. J. Exp. Biol. 94: 77-94.
Gardner, D. (1977) Interconnections of identified multiaction interneurons in buccal ganglia of Aplysia. J. Neurophysiol. 40: 349-361.

Gorman, A. L. F., and M. Mirolli (1969) The input-output organization of a pair of giant neurones in the mollusc Anisodoris nobilis. J. Exp. Biol. 51: 615-634.

Groves, P. M., and R. F. Thompson (1970) Habituation: A dualprocess theory. Psychol. Rev. 77: 419-450.

Hawkins, R. D., T. W. Abrams, T. J. Carew, and E. R. Kandel (1983) A cellular mechanism of classical conditioning in Aplysia: Activitydependent amplification of presynaptic facilitation. Science 219:400405 .

Hurvich, L. M., and D. Jameson (1957) An opponent-process theory of color vision. Psychol. Rev. 64: 384-404.

Kandel, E. R., and J. H. Schwartz (1982) Molecular biology of learning: Modulation of transmitter release. Science 218: 433-443.

Kupfermann, I. (1974a) Feeding in Aplysia: A simple system for the study of motivation. Behav. Biol. 10:1-26.

Kupfermann, I. (1974b) Dissociation of the appetitive and consumatory phases of feeding behavior in Aplysia: A lesion study. Behav. Biol. 10: 89-97.

Kupfermann, I., and K. R. Weiss (1982) Activity of an identified serotonergic neuron in free moving Aplysia correlates with behavioral arousal. Brain Res. 241: 334-337.

Lloyd, P. E., I. Kupfermann, and K. R. Weiss (1984) Evidence for parallel actions of a molluscan neuropeptide $\left(\mathrm{SCP}_{\mathrm{b}}\right)$ and serotonin in mediating arousal in Aplysia. Proc. Natl. Acad. Sci. USA 81: 29342937.

MacFarland, F. M. (1909) The Opisthobranch Molluscs of the Branner-Agassiz Expedition to Brazil, Stanford U.P., Stanford, CA.

Masterson, F. A., and M. Crawford (1982) The defensive motivation system: A theory of avoidance behavior. Behav. Brain Sci. 5: 661689.

McClellan, A. D. (1982) Reexamination of presumed feeding motor activity in the isolated nervous system of Pleurobranchaea. J. Exp. Biol. 98: 213-228.

Pantin, C. F. A. (1946) Notes on Microscopical Techniques for Zoologists, Cambridge U.P., Cambridge, UK (reprinted 1969).

Reingold, S. C., and A. Gelperin (1980) Feeding motor programme in Limax. II. Modulation by sensory inputs in intact animals and isolated central nervous systems. J. Exp. Biol. 85: 1-20.

Schwarz, M., and Susswein, A. J. (1984) A neural pathway for learning that food is inedible in Aplysia. Brain Res. 294: 363-366.

Senseman, D. M. (1978) Short-term control of food intake by the terrestrial slug Ariolimax. J. Comp. Physiol. 124: 37-48.

Sigger, J. N., and D. A. Dorsett (1981) Synaptic actions of the oesophageal proprioceptors in the mollusc, Philine. J. Exp. Biol. 94: 95-104.

Solomon, R. L., and J. D. Corbit (1974) An opponent-process theory of motivation. Psychol. Rev. 81: 119-145.

Susswein, A. J. (1975) Studies on satiation of feeding in the marine mollusc Aplysia, Ph.D. dissertation, New York University, NY.

Susswein, A. J., and M. V. L. Bennett (1979) Plasticity of feeding behavior in the opisthobranch mollusc Navanax. J. Neurobiol. 10: 521-534.

Susswein, A. J., and I. Kupfermann (1975a) Bulk as a stimulus for satiation in Aplysia. Behav. Biol. 13: 203-209.

Susswein, A. J., and I. Kupfermann (1975b) Localization of bulk stimuli underlying satiation in Aplysia. J. Comp. Physiol. 101: 309328.

Susswein, A. J., I. Kupfermann, and K. R. Weiss (1976) The stimulus control of biting in Aplysia. J. Comp. Physiol. 108: 75-96.

Susswein, A. J., K. R. Weiss, and I. Kupfermann (1984) Internal stimuli enhance feeding behavior in the mollusc Aplysia. Behav. Neural Biol. 41: 90-95.

Susswein, A. J., M. Schwarz, and E. Feldman (1986) Learned changes of feeding behavior in Aplysia in response to edible and inedible foods. J. Neurosci. 6: 1513-1527.

Walters, E. T., and J. H. Byrne (1983) Associative conditioning of single sensory neurons suggests a cellular mechanism for learning. Science 219: 405-408.

Weiss, K. R., J. L. Cohen, and I. Kupfermann (1978) Modulatory control of buccal musculature by a serotonergic neuron (Metacerebral Cell) in Aplysia. J. Neurophysiol. 41: 181-203.

Weiss, K. R., U. T. Koch, J. Koester, D. E. Mandelbaum, and I. Kupfermann (1981) Neural and molecular mechanisms of food induced arousal in Aplysia californica. Adv. Physiol. Sci. 23: 305-344. 